\title{
Less Commonly Taught Slavic Languages: The Learner, the Instructor, and the Learning Experience in the Second Language Classroom (A North American Context)
}

\author{
Alla Nedashkivska \\ Guest Editor, University of Alberta
}

$\mathrm{T}$

he initial goal of this special section of the EWJUS was to explore and synthesize current developments in the field of Second Language Acquisition and Language Pedagogy, focusing specifically on less commonly taught Slavic languages (LCTSL henceforth) in a North American context. The call for papers encouraged both theoretical and empirical studies that focused on the Learner, the Instructor, and the Learning Experience in the Second Language Classroom. The special section that follows offers a selection of scholarly inquiries that address all three foci, with "the Learner" at the core of each scholarly inquiry. The special section consists of three articles and five reports from the field. The articles, which are theoretically and empirically grounded, address the most pressing issues of LCTSL and focus on Czech, Bosnian-Croatian-Serbian (BCS), and Ukrainian. The reports from the field familiarize readers with current developments and innovations in programs, teaching practices, learning resource developments, and course initiatives in various programs that offer LCTSL (Polish, Slovak, and Ukrainian are represented).

The three articles in this special section, by Susan Kresin, Danko Šipka, and Alla Nedashkivska and Olena Sivachenko, are closely interconnected. All three represent a scholarly response to the challenges LCTSL face in today's globalized world and economy, as well as a changing academic climate marked by declining enrollments, administrative pressures to secure enrollments, a decrease in funding for smaller programs, and the reduced viability of Slavic and East European programs at postsecondary institutions. The articles approach these challenges by assessing the practices of teaching and learning today, focusing specifically on today's learners. By studying different language contexts of LCTSL, all three articles stress the necessity of researching our learners' needs, which enables us to react to shifts in the rapidly changing academic and economic landscape. The three articles are presented in the order of their research foci's interconnectedness and are discussed accordingly. 
Kresin and Šipka focus their investigations on heritage language learners' communities and outline the heightened academic interest in heritage language education over the past two decades. Both authors then highlight questions of language maintenance in these and other heritage communities. Kresin's and Nedashkivska and Sivachenko's articles relate to the prominent role of motivation. Kresin touches upon parent and also student motivations to maintain and study heritage languages. Nedashkivska and Sivachenko specifically focus on factors that motivate and demotivate postsecondary students to enroll in Ukrainian studies. Both Šipka and Nedashkivska and Sivachenko note the importance of technology in today's learning process (online and hybrid courses). Overall, the three articles elevate "the Learner" as the centre of inquiry.

Kresin discusses the new wave of globally connected, transnational heritage communities, and points out the new shifts in attitudes toward learning heritage languages that include "appreciation of the cultural, social, political, and economic benefits." Focusing on heritage language learners, Kresin draws a picture of a heritage learner, allowing us to better understand this particular student population. She lucidly describes common characteristics of a heritage language learner: stronger receptive than productive language skills; higher functioning in informal speech modes rather than formal and academic settings; a faster pace of learning the language in comparison to a typical L2 learner; the constantly changing "dynamic condition" of bilingualism of heritage learners; code-switching and language interference; and the baseline language of heritage language learners, which is not always the standardized literary language taught in language programs. Kresin also shows how these characteristics of heritage language learners have consequences for pedagogical practices and offers a discussion of how pedagogical materials may be tailored to individual students' abilities, interests, and needs.

As an applied focus of the study, Kresin offers some suggestions about the types of texts and activities useful in a mixed heritage-L2 class. Kresin shares recommendations on the following: how films could be used and tailored to different student audiences in the same classroom; how independent research projects and presentations provide heritage students with opportunities to work with academic registers; how independent reading activities foster the development of students' background knowledge, topic-specific vocabulary, and pragmatic elements of various registers in different contexts; how contemporary media texts promote students' curiosity toward contemporary language norms; and how community-learning practices incorporated into the learning process promote students' exposure to different registers, a variety of language variants and accents, and etiquette conventions, thereby strengthening their engagement with the target language and culture. In mixed-language 
classrooms, or differentiated language classrooms, these practical suggestions are extremely helpful in building on language learners' strengths, rather than viewing heritage language learners as challenges in the classroom. Kresin concludes on a positive note that now is the time to invest in further research of heritage learners' communities, which allows for successfully meeting the challenges of teaching mixed heritage and nonheritage language classes.

Focusing on learners of BCS, Šipka discusses possible pathways to, and heritage language learners' attitudes toward, the attainment of full professional language proficiency. Šipka begins by addressing challenges associated with BCS in the United States, including the interethnic tensions that still exist. He reports on the interviews and survey data, the analyses of which he uses for the development of a new course for heritage language learners. Šipka's results demonstrate that with respect to language learning, and language maintenance in particular, the role of parents is paramount (the author notes a need for a strong outreach component toward the parents, which is worthy of further study). He also discusses the less important factors for language development and maintenance, such as proximity to locations where the heritage language is spoken and opportunities to engage with the target culture, as well as the influence of cultural elements, such as traditions and food. Interestingly, with respect to learners' needs and desires, Šipka finds that learners demonstrate a strong preference for online language courses. Importantly, he focuses on how learners perceive their own language accuracy and needs. As can be expected in this respect, learners view their writing and formal language skills as weak. Yet, contrarily, they believe their speaking and listening/comprehension abilities to be quite high. Šipka views such beliefs as inflated and in need of contesting. The author's statistical data, a representative sample of 154 participants, show some interesting results. The data demonstrate the importance of study abroad in heritage language learning and how it correlates with higher self-assessment by learners. Worthy of note are the following statistics: $97.9 \%$ of respondents want to learn BCS and $97.3 \%$ want to teach their children the language, but only $65 \%$ of respondents are interested in heritage language classes. Moreover, there is a curious finding whereby none of the factors discussed in the study shows any statistically significant correlation with an interest in heritage language classes. Even more so, there is a statistically significant negative correlation between an interest in heritage language classes and heritage language used at home (that is, the more the language is used at home, the less is the interest in studying the language formally).

These results are in need of further development and Šipka stresses the need to change heritage language learners' perceptions about their high selfassessment of language abilities (please note that these results echo with 
heritage learners' perceptions of "already accomplished goals," as noted in Nedashkivska and Sivachenko's article). Šipka, following his analyses, presents a design of a new course that tailors heritage learners' needs based on empirical data. This pilot is small, comprising only three students, but nevertheless offers some interesting insights into pedagogical design. The author concludes with final recommendations that relate to factors in heritage language maintenance, as well as teaching and learning. The author ends with a call for a national centre for BCS heritage language maintenance and learning, one which would support BCS language and culture education, and coordinate efforts toward the development and sustainment of BCS programs, courses, and activities.

Focusing on the learner, Nedashkivska and Sivachenko present their study on what motivates and what demotivates today's students to enroll in Ukrainian studies. The authors also offer recommendations based on their empirical research. Nedashkivska and Sivachenko study current, past, and also potential learners, both quantitatively and qualitatively. Their quantitative results measure the motivational profiles of participants. The authors relate their qualitative approach to students' perspectives on how learners' motivation relates to their learning experiences, present or potential. Nedashkivska and Sivachenko conceptualize motivation at three levels, which they established for the analysis: a) the subject area level; b) the learner level; and c) the learning situation level. Their quantitative analysis, based on responses received from sixty participants, demonstrates interesting tendencies and differences among the groups studied. Alarming in their data set is the fact that "language learners," that is, students enrolled in language classes at the time of the survey, show the lowest selfconfidence, the highest levels of anxiety, and more demotivators when compared to other groups with respect to the atmosphere in the classroom, course load, teaching materials, and methods. These results deserve more detailed examination. In particular, do these results indicate the highest levels of anxiety in lower level language classes or lower level classes overall? Which specific factors contribute to such low levels of selfconfidence, and do these relate to the students' early term of exposure to postsecondary studies? Based on data collected and analyzed, the authors do not have a clear answer to these questions.

Nedashkivska and Sivachenko's qualitative analysis offers a more elaborate look into motivating and demotivating factors. Interestingly, among the demotivators they find are the learners' perceptions of accomplished goals, which weaken their desire to study Ukrainian at the postsecondary level (as stated above, similar findings are noted by Šipka with respect to BCS). In addition, the authors note that among the demotivators students reported were their lack of knowledge about course offerings and course relevance to their degrees, which prevented or 
discouraged them from enrolling in Ukrainian studies. Importantly, the authors find that differences in students' proficiency levels figured as noticeable demotivators. With respect to textbooks, the authors report on students' desire for resources that are technologically enhanced and applicable to real-life situations. Overall, Nedashkivska and Sivachenko raise several important questions for those involved in teaching Ukrainian studies, but also other LCTSL. The authors conclude with a set of recommendations that they formulate based on their analysis. These are relevant to teaching materials and instructional methods, variants of language taught, challenges of differentiated classroom and assessment methods, marketing of the programs, and, importantly, understanding the learning situation and knowing the contemporary learner.

Reports from the field constitute an important addition to the special section, providing rich information about new and exciting developments in courses and programs of LCTSL. These reports also address challenges we face with LCTSL offerings and how we as scholars and educators respond to these challenges in innovative and creative ways. This section addresses the following topics: potential shifts in focus from lesser-taught languages to lesser-taught cultures (Martin Votruba), development of special teaching and learning materials for heritage learners (Anna Zofia Gąsienica Byrcyn), incorporation of technology into language teaching and learning (Kinga Kosmala and Erik Houle; Olena Sivachenko and Alla Nedashkivska), and creation of Web-based resources for cultural studies that also contribute to student training (Natalie Kononenko).

Votruba begins by discussing various LCTSL and prospects that might exist for the teaching of Slavic languages in North America. The author questions the very concept of "lesser-taught" languages and which languages are to be included in this category, also introducing the concept of "never taught" Slavic languages. Votruba describes the case of Slovak studies at the University of Pittsburgh, and how the program responds to new realities and interests of today's students. The author problematizes the von Herder concept of language and culture, applying it to his discussion of new goals that North American Slavic programs may currently have. The author ends with some recommendations for Slavic departments to consider, for example, offering "lesser-taught culture" courses in English, rather than focusing predominantly on language instruction.

Gąsienica Byrcyn focuses on teaching and learning materials for Polish as a foreign language and discusses the use of poetic texts as resources for heritage learners' of Polish. The author illustrates how a poetic text may be used as an immersive cultural experience for a language learner and how particular texts could be adapted to different levels of language proficiency and instruction. Gąsienica Byrcyn also demonstrates the importance of poetic texts for the acquisition of different language skills and grammatical 
elements. The author lays out examples from Polish that include not only the poetic texts chosen by the instructor, but also students' own creations and adaptations of these texts-exercises likely to inspire similar experiments in other heritage learning contexts.

Kosmala and Houle, also focusing on resources for Polish, inform us about their project that aims to enhance Polish language learning experiences with cultural information. The authors report on their development of supplementary online resources that accompany the series Hurra!!! po polsku I, II, III, but are also adaptable to other textbooks for teaching Polish as a foreign language. Kosmala and Houle describe their pedagogical considerations in creating the discussed technologically enhanced resources, the objectives of which are to broaden students' knowledge of Polish daily life, culture, history, geography, and traditions. The authors inform us about the various cultural texts they use for creating rich and diverse learning opportunities for students to engage with cultural input, such as videotexts, a cultural portfolio, and others.

Sivachenko and Nedashkivska present their newly developed blendedlearning resources (a combination of face-to-face and online components), entitled Подорожі.UA for the beginners' Ukrainian learner. Focusing on technologically enhanced language learning and instruction, the authors discuss the structure, methodological considerations, pedagogical design, and technological tools that relate to the creation of the blended-learning model textbook. Sivachenko and Nedashkivska also report on their piloting of these resources, briefly address learners' perceptions of the effectiveness of the model, and discuss their responses to challenges encountered during the pilot phase. The authors end on an enthusiastic note and invite others to try this model.

Kononenko discusses her extensive work on the Ukraine Alive project, a Web-based resource that features contemporary cultural materials. These resources and pedagogical tools are currently in demand at various educational levels from elementary to postsecondary, impacting other disciplines and cultures. Interestingly, university students generate some of the content in these technologically enhanced resources, which affords them the opportunity to gain training in formal composition for online presentation. Kononenko concludes by mentioning her new project, an interactive game of Ukrainian culture and beliefs, leaving us eager to learn more about her new endeavour.

In concluding this introduction, I note that in recent years there has been an increased interest in LCTL, and in Slavic languages in particular. This is most visible in panels, round tables, and poster sessions devoted to LCTSL during recent American Association of Teachers of Slavic and East European Languages conferences. All articles and reports from the field, offered in the special section of this issue, contribute to this growing body of scholarly 
inquiry. Studies presented in this issue offer opportunities to engage in a discussion with those of us interested in LCTSL at the postsecondary level, as well as those concerned with broader questions of foreign language learning. The research questions that we may pose with respect to the Learner, the Instructor, and the Learning Experience are endless, yet crucial, not only for our own academic existence, but also for the well-being of the field. Such studies, as well as their findings, remain on the periphery of our academic inquiries, be they individual or collective. It is therefore important that the present collection stimulates further scholarly exchange. 